\title{
Overactive bladder in children
}

\author{
Sophie Ramsay, MD;' Stéphane Bolduc, MD ${ }^{1,2}$
}

'Division of Urology, CHU de Québec-Université Laval, Quebec City, QC Canada; ${ }^{2}$ RCHU de Québec-Université Laval, Quebec City, QC, Canada and Axe Médecine Régénératrice

Cite as: Can Urol Assoc J 2017;11 (1-2Suppl1):S74-9. http://dx.doi.org/10.5489/cuai.4337

See related commentary on page $\$ 80$.

\section{Abstract}

Overactive bladder $(\mathrm{OAB})$ is a highly prevalent disorder in the pediatric population. This condition is especially troublesome for pediatric patients and their families when associated with incontinence, since it negatively affects self-esteem and impairs children's development. From the patient's perspective, urgency and urge incontinence can have a significant impact, negatively affecting their quality of life. For a therapy to have true benefit, changes must not only be statistically significant, but must also be perceived as meaningful by the patient. A stepwise approach is favoured to treat this pathology, starting with behavioural therapy, followed by medical management, and eventually more invasive procedures.

Antimuscarinic agents are the mainstay of medical treatment for $\mathrm{OAB}$. Oxybutynin is the most commonly used antimuscarinic in the pediatric population. However, some patients have a suboptimal response to antimuscarinics and many experience bothersome side effects, which have been documented with all antimuscarinics to a significantly higher degree than placebo. Although there have been reports about the use of tolterodine, fesoterodine, trospium, propiverine, and solifenacin in children, to date, only oxybutynin has been officially approved for pediatric use by medical authorities in North America.

This review will address alternative treatment options for pediatric patients presenting with $\mathrm{OAB}$, from conservative measures to more invasive therapies.

\section{Introduction}

As per the International Children's Continence Society, overactive bladder (OAB) is "urinary urgency, usually accompanied by frequency and nocturia, with or without urinary incontinence, in the absence of urinary tract infection or other obvious pathology, ${ }^{\prime 1}$ and it is the most common voiding dysfunction in children. ${ }^{2}$ According to two fairly recent, large-scale studies, the prevalence of OAB in children is in the $15-20 \%$ range. ${ }^{3-4}$ Those studies both reported a higher prevalence of OAB in boys. Chung et al noted a decreasing prevalence of $\mathrm{OAB}$ with age, from $23.0 \%$ at five years old down to $12.2 \%$ at 13 years old. ${ }^{4}$

$\mathrm{OAB}$ has a damaging impact on quality of life $\mathrm{e}^{5}$ and $\mathrm{a}$ negative influence on social, emotional, and behavioural well-being. ${ }^{6}$ Quality of life improvement is at the foundation of OAB treatment, which can often be challenging and might involve multiple failed attempts before success is achieved.

This article will focus on the management of $O A B$ in children, including discussion about medications and more invasive treatment modalities not yet approved for use in this population.

\section{Diagnostic workup}

See previous article by Dos Santos et al on the diagnosis and treatment of bladder and bowel dysfunction in children.

\section{Conservative management}

Children and families need to be educated about OAB and expectations from the different management options in order to have realistic treatment goals. In any case, timed voiding every two to three hours during daytime, should be instituted early on $^{7}$ and the child should have sufficient periods of time to achieve complete emptying. Parent and school collaboration is critical to the establishment of this voiding routine and positive reinforcement with rewards or a multi-alarm watch might be helpful for this endeavor. In terms of voiding technique, children should void with their legs spread apart and a footstool should be used for the child's heals to touch the ground if the toilet does not have a proper height. A 50\% improvement rate of frequency and urgency symptoms has been reported in children after simple behavioural therapy. ${ }^{8}$

Concerning fluid intake, it has to be regular during the day, but minimalized towards bedime. Beverages that can trigger urgency and frequency symptoms, such as those containing caffeine, chocolate or citrus, and carbonated beverages should be avoided.

Until proven otherwise, all children with bladder disorders are constipated, ${ }^{9}$ hence the necessity for prompt and 
aggressive bowel management in these patients. In a 1997 article, Loening-Baucke reported that the relief of chronic constipation resulted in disappearance of daytime urinary incontinence and nighttime incontinence in $89 \%$ and $63 \%$ of patients, respectively. ${ }^{10}$ Because parents are often not the best judges of their children's bowel habits, children must be questioned directly on the subject. The Bristol stool scale is an invaluable tool for this purpose. Staying well hydrated and having a high-fiber diet are fundamental to a good bowel regimen. Laxatives are often necessary and an initial bowel clean-out is occasionally required.

Biofeedback therapy allows better understanding and perception of the pelvic musculature and, therefore, induces greater pelvic floor control. Significant improvements are anticipated not only in children with dysfunctional voiding, but also in those with OAB. ${ }^{11}$

When the decision is taken to introduce a medication in the treatment plan of the child with $O A B$, conservative measures must be continued.

\section{Pharmacological treatment options}

\section{Oxybutynin}

The immediate-release (IR) (Ditropan ${ }^{\circledR}$ ) and extended-release (ER) (Ditropan $\mathrm{XL}^{\circledR}$ ) formulations of oxybutynin are currently the only pharmacological agents approved for the treatment of $\mathrm{OAB}$ in children in North America. ${ }^{12}$

Although IR oxybutynin is the antimuscarinic agent with the longest history of use in children, no studies have yet compared it to placebo. Its use in the pediatric population is based on small observational studies and extrapolated from its use in adults. Side effects include xerostomia, dry eyes, dry skin, constipation and gastrointestinal disturbances, flushing, blurred vision, dizziness, and sleep difficulties, which can be sufficiently bothersome to necessitate reduction of the dose or discontinuation of the medication. ${ }^{13-16} \mathrm{IR}$ oxybutynin is offered as a $5 \mathrm{mg}$ tablet and a $1 \mathrm{mg} / \mathrm{ml}$ suspension. The recommended daily dose is $0.3-0.6 \mathrm{mg} / \mathrm{kg}$ and the maximum dose is $15 \mathrm{mg} / \mathrm{kg} /$ day. For children over five years of age, a $5 \mathrm{mg}$ dose twice daily is an appropriate starting regimen and the dose can be increased to three times a day if symptoms persist. The main drawbacks of IR oxybutynin are its side effect profile and its administration schedule.

ER oxybutynin has been shown to be superior to the IR form in various studies. ${ }^{17-19}$ For instance, Van Arendonk et al reported cure or significant clinical improvement in $48 \%$ of the children they evaluated after they switched from the IR to the ER formulation. ${ }^{17}$ Preliminary studies reported less frequent adverse effects with ER compared to IR oxybutynin, ${ }^{18}$ but other studies did not note a difference. ${ }^{17} \mathrm{ER}$ oxybutynin is administered once daily and is available as a $5 \mathrm{mg}$ or $10 \mathrm{mg}$ tablet which, unfortunately, needs to be swallowed intact. In children over five years of age, one should start with a $5 \mathrm{mg}$ tablet and increase the dose progressively, up to a maximum of $20 \mathrm{mg} /$ day, until therapeutic efficacy is achieved.

There is a paucity of literature on the use of the oxybutynin transdermal delivery system $\left(\mathrm{Oxytrol}^{\circledR}\right)$ in children. The only paper addressing the subject is from the Toronto group. In 2014, they reported a subjective symptomatic improvement in $96 \%$ of their patients, $69 \%$ of which had prior exposure to oral oxybutynin. ${ }^{20}$ They stated skin irritation as the most common side effect, with a $35 \%$ occurrence rate. The transdermal system comes in the form of an adhesive patch delivering $3.9 \mathrm{mg}$ of oxybutynin per day and that needs to be changed twice per week. The patch needs to be applied to dry, intact skin on the abdomen, hips, or buttocks, and reapplication to the same area should be avoided within a one-week period. ${ }^{20} \mathrm{~A}$ second partial or complete patch can be applied if the initial dosage is unsatisfactory.

Efficacy of the topical gel formulation of oxybutynin $\left(G e l n i q u e^{\circledR}\right)$ has been demonstrated in adults with $\mathrm{OAB}$ in two randomized, placebo-controlled trials. ${ }^{21,22}$ However, as of now, there is no data on its efficacy or safety in children.

Intravesical instillations of a single dose of oxybutynin have shown promising results in adults. ${ }^{13,14}$ Improvements have also been reported in children with neurogenic $O A B,{ }^{13,23}$ but no studies have yet been conducted in neurologically intact children, possibly because of the need for catheterization. Intravesical oxybutynin has not been associated with significant side effects. ${ }^{14,23-25}$ The solution is usually prepared by crushing and dissolving a $5 \mathrm{mg}$ tablet of oxybutynin in $30 \mathrm{~mL}$ of distilled water. For the non-neurogenic patients, intravesical instillations should be reserved for refractory cases and highly motivated children and families, who are willing to perform catheterization in a sensate urethra.

\section{Investigational drugs}

\section{Other antimuscarinic agents}

The IR release $\left(\right.$ Detrol $\left.^{\circledR}\right)$ and ER (Detrol LA ${ }^{\circledR}$ ) formulations of tolterodine are currently approved for the treatment of $\mathrm{OAB}$ in adults. Several studies have supported its efficacy and tolerability in children. ${ }^{26-29}$ Although Reinberg et al have shown that ER oxybutynin is more effective than both forms of tolterodine for the control of daytime urinary incontinence and frequency, ${ }^{19}$ a review by Medhi et al advocated that tolterodine was as effective as oxybutynin, but with fewer side effects. ${ }^{28}$ Bolduc et al reported in their study that $77 \%$ of children who were started on tolterodine because they could not tolerate oxybutynin continued treatment with no significant side effects. ${ }^{27}$ The IR tolterodine formulation is available as a $1 \mathrm{mg}$ or $2 \mathrm{mg}$ tablet and the ER formulation is available as a $2 \mathrm{mg}$ or $4 \mathrm{mg}$ tablet. 
Fesoterodine $\left(\right.$ Toviaz $\left.^{\circledR}\right)$ is the newest ER antimuscarinic agent and comes as a $4 \mathrm{mg}$ or $8 \mathrm{mg}$ tablet. Its efficacy is based on the same active metabolite (5-hydroxy-methyltolterodine [5-HMT]) as tolterodine, but with less pharmacokinetic variability. ${ }^{30}$ In a 2012 study, Malhotra et al demonstrated that daily administration of fesoterodine in children over $25 \mathrm{~kg}$ produced similar 5-HMT plasmatic concentrations as those seen in aduls and that the medication was safe and tolerable in children. ${ }^{31}$ Our group is presently conducting a randomized, double-blind, crossover study comparing the efficacy and tolerability of fesoterodine and ER oxybutynin in 60 children with $\mathrm{OAB}$ as well as a 12-month extension study to assess the efficacy and safety of fesoterodine. Both studies are still recruiting patients (see Clinicaltrials.gov).

Solifenacin $\left(\right.$ Vesicare $\left.^{\circledR}\right)$ is another long-acting antimuscarinic molecule and is offered as a $5 \mathrm{mg}$ or $10 \mathrm{mg}$ tablet. In a retrospective study of 138 children treated with solinefacin for 23 months, Hoebeke et al noted an overall response rate of $85 \%$ and occurrence of side effects in $6.5 \%$ of their population. ${ }^{32}$ In a prospective, open-label trial on 72 chilren, Bolduc et al noted improved continence in all of their patients, but because of unmanageable side effects, four of their patients had to withdraw from the study. ${ }^{33}$ In an extension of this study, Nadeau et al reported an overall success rate of $94 \%$, with greater benefits being observed with higher doses. ${ }^{34}$ Newgreen et al presented results from a phase 3, randomized trial. They compared solifenacin and urotherapy to placebo and urotherapy in the treatment of children with $O A B$. They noted a greater increase in the mean voided volume in the solifenacin group, as well as a significant decrease in urinary frequency when analyses were adjusted for change in fluid intake. ${ }^{35}$ In an extension of this study, Bosman et al reported that solifenacin was effective and well tolerated in children. ${ }^{36}$

Trospium (Trosec ${ }^{\circledR}$, Sanctura ${ }^{\circledR}$ ) is available as a $20 \mathrm{mg}$ tablet in Canada. Early trials in children showed promising results, ${ }^{37,38}$ but no new reports have been published in the last decade. At the 2015 European Society for Paediatric Urology (ESPU) Congress, Wright et al presented a retrospective study of 13 children, most of which had a previous history of central nervous system (CNS) adverse events while on other antimuscarinic agents. Only one child had CNS side effects while on trospium. ${ }^{39}$

Propiverine for $\mathrm{OAB}$ treatment is neither approved for adults nor children in Canada and the U.S. (approaval under evaluation), but it is available in Europe and Asia in IR and ER formulas (23 countries). Its efficacy in children has been assessed in a multicentre, placebo-controlled, double-blind study that demonstrated significant improvement in urinary frequency, incontinence episodes and mean voided volume. ${ }^{40} \mathrm{Kim}$ et al reported an overall response rate of $86.8 \%$ in a retrospective review of 68 children. ${ }^{41} \mathrm{~A}$ multicentre, observational, cohort study comparing propiverin to oxybu- tynin demonstrated that propiverine was at least as effective as oxybutynin and that it had a favourable tolerability profile over oxybutynin. ${ }^{42}$

\section{Beta-3 agonist}

Mirabegron (Myrbetriq ${ }^{\circledR}$ ) is a beta-3 agonist approved for the treatment of $O A B$ in adults and is available as ER tablets of $25 \mathrm{mg}$ and $50 \mathrm{mg}$. Its efficacy and tolerability in adults has been recognized in five large-scale, phase 3, randomized, controlled trials. ${ }^{43}$ Side effects commonly encountered with antimuscarinics, such as xerostomia, constipation, and headaches, have not been reported more often than placebo with mirabegron. ${ }^{44}$ Because of minor changes in heart rate and blood pressure observed with mirabegron, a periodic monitoring of blood pressure is warranted for patients with cardiovascular morbidities taking this medication..$^{45}$ There is very scarce data on the use of mirabegron in the pediatric population. Blais et al enrolled 58 children with refractory $\mathrm{OAB}$ in a prospective, open-label study, and treated them with mirabegron for 11.5 months. They reported a statistically significant improvement in bladder capacity and continence with the occurrence of mild or moderate side effects in eight patients. ${ }^{46}$ Mirabegron might be considered as an off-label option in children who cannot tolerate antimuscarinics or with refractory $\mathrm{OAB}$.

\section{Dual therapy}

Combination therapy with two antimuscarinics has been minimally studied in the pediatric population. Bolduc et al reported on 33 children treated with dual antimuscarinic therapy. Continence was improved in all patients with refractory $\mathrm{OAB}$, but mild or moderate side effects were reported in $63 \%$ of patients. However, they were not severe enough to necessitate discontinuation of the medication. ${ }^{47}$ In a 36-month extension phase of this study including 56 patients, $41 \%$ of patients were dry and $32 \%$ were improved; $50 \%$ experienced mild or moderate side effects, with two patients requiring a different treatment regimen because of troublesome side effects. ${ }^{48}$ Our group also recently reported on a prospective, open-label study to assess dual therapy with an antimuscarinic agent and mirabegron. Our results are promising, with improvement of continence in all 35 patients and mild side effects in only four patients. ${ }^{49}$ Finally, in 2016, Fahmy et al evaluated 72 children with persistent urinary symptoms despite taking an optimized dose of oxybutynin, and treated with an add-on dose of trospium. Their overall success rate was $68 \%$, with $57 \%$ of children reporting no side effects. However, two patients had to withdrew from the study because of unbearable side effects. ${ }^{50}$ 


\section{Medication adherence and persistence}

Medication adherence and persistence are central to any treatment success, but literature pertaining to the pediatric population with $\mathrm{OAB}$ is lacking. Adherence is dreadful in adults taking antimuscarinic medications, with one recent study reporting adherence rates at 12 months of 35.8, 31.9, and $30.9 \%$ for fesoterodine, solifenacin, and tolterodine, respectively. ${ }^{51}$ In a study pending publication, our group noted a medication possession ratio over $80 \%$ in only $64 \%$ of children treated with antimuscarinics. ${ }^{52}$ Although this is better than what has been described in adults, strategies are required to increase adherence and, thus, improve treatment efficacy.

Persistence to antimuscarinic agents is also appaling in adults, with Wagg et al showing that only $14-35 \%$ of patients remained on their initial therapy at 12 months. ${ }^{53}$ Our group recently published a restrospective review of 374 children treated with antimuscarinics over a four-year period, at the end of which only $11.8 \%$ of patients were still taking an antimuscarinic medication. ${ }^{54}$ Even though a percentage of the children who discontinued their antimuscarinics might be attributable to the disappearance of OAB symptoms, persistence in children must be further investigated, as it definitely influences treatment success.

\section{Invasive treatment options}

\section{Intradetrusor injections of botulinum toxin}

Although injections of botulinum toxin A (BoNTA) have been approved for the treatment of $O A B$ in adults for a few years, they are currently solely offered as an off-label, second-line option in children. Several formulations of the toxin are available, but most studies concern onabotulinumtoxinA (Botox ${ }^{\circledR}, 100$ unit vials, Allergan, Irvine, CA, U.S.). BoNTA is contra-indicated in patients with peripheral motor neuropathic diseases, neuromuscular junction disorders, active untreated urinary tract infection (UTI), uncorrected coagulopathy, and pregnancy. Additionally, since BoNTA dose is cumulative, precautions should be taken when treating children with spasticity, as they may be receiving BoNTA at other sites in the same time period. The suggested age threshold for BoNTA use in children is three years old ${ }^{55}$ and the recommended dosage is $5-10$ units per kilogram of body weight. ${ }^{55}$ For children with idiopathic OAB, 50-100 units are commonly used, ${ }^{56}$ while up to $200-300$ units can be used for those with neurogenic OAB. The estimated lethal dose is estimated at 40 units per kilogram. The technique of injection is similar as in adults with the exception that the procedure is almost exclusively performed under general anesthesia in the pediatric population. Prophylactic antibiotics are recommended, but aminoglycosides should be avoided, as they are known to potentiate the effect of BoNTA. The effect of BoNTA injections in children lasts from 5-12 months with no apparent tachyphylaxis. ${ }^{56}$ Repeated injections should be spaced by a minimum of 12 weeks. Side effects, such as pain, UTI, hematuria, and autonomic dysreflexia, occur in $20 \%$ of patients and are mostly procedure-related. ${ }^{57}$ From $2-9 \%$ of patients will experience partial or complete urinary retention following the injections. ${ }^{56,58}$ Thus, children and families must be willing to perform clean intermittent catheterization $(\mathrm{CIC})$ before agreeing to the procedure. Systemic absorption can lead to more severe side effects, including respiratory depression requiring mechanical ventilation. Improvement in clinical and urodynamic parameters with durability of effect over time in the pediatric population has been demonstrated in five level 3 studies with response rates ranging from $44-95 \% .{ }^{56,58}$

\section{Neuromodulation}

Similarly to BoNTA, neuromodulation is approved for cases of refractory $\mathrm{OAB}$ in adults, but despite a growing body of evidence, its use is currently off-label in the pediatric population. Several nerve stimulation technique exist and have been assessed in children with OAB.

Intravesical electrical stimulation (IVES) appeared promising a couple of decades ago, with a cure rate of $26 \%$ and improvement rates ranging from $33-80 \%, 59,60$ but a later randomized, blinded, sham-controlled study did not report significant differences between IVES and sham groups. ${ }^{61}$ With conflicting results and the need for multiple sessions, potentially up to a few hundred times, IVES is not commonly used in children.

Although favourable outcomes have been noted with functional electrical nerve stimulation, ${ }^{62,63}$ its use is limited, as it involves stimulation of the anal and genital regions.

Transcutaneous electrical nerve stimulation (TENS) has consistently demonstrated encouraging results in children. Earlier uncontrolled studied reported improvement and cure rates of $\mathrm{OAB}$ or lower urinary tract dysfunction from 56-100\%. ${ }^{64,65}$ Two sham-controlled studies showed similar results, ${ }^{66,67}$ as has a 2015 uncontrolled study reporting complete and partial response rates of 70 and $22 \%$, respectively. ${ }^{68}$ Recently, two groups compared TENS to approved treatment options for $\mathrm{OAB}$ in children. Sillén et al found no significant differences in a randomized trial comparing urotherapy alone to urotherapy and TENS. ${ }^{69}$ Likewise, Quintiliano et al confronted oxybutynin to TENS and concluded that they had similar efficacy. ${ }^{70}$ Moreover, a recent cost-effectiveness analysis favoured TENS over antimuscarinic medications in children with OAB. ${ }^{71}$

Percutaneous tibial nerve stimulation (PTNS) has been associated with positive results in uncontrolled studies. ${ }^{72}$ In 2015, two groups published randomized, sham-controlled tri- 
als using a transcutaneous approach, therefore, dismissing the need for the percutaneous needle insertion. Though Patidar et al reported a cure rate of $67 \%$ and an improvement rate of $24 \%$ in the PTNS group, compared to $0 \%$ and $6 \%$, respectively, in the sham group, ${ }^{73}$ Boudaoud et al noted a similar clinical efficacy between their PTNS and sham groups. ${ }^{74}$

Sacral neuromodulation with an implantable device, such as InterStim ${ }^{\circledR}$, is commonly performed in adults with refractory $\mathrm{OAB}$, but thus far, the pediatric literature is scarce. In 2015, Schober et al concluded significant improvement in voiding dysfunction scores and in urodynamic parameters in a group of 23 children with OAB. ${ }^{75}$ Sacral neuromodulation might be a possibility for judiciously selected children with unmanageable OAB.

\section{Conclusion}

In conclusion, with a significant prevalence in children, $\mathrm{OAB}$ is a burdensome and challenging condition for physicians. A proper evaluation of children with lower urinary tract symptoms is critical and correctable contributing factors, such as constipation, should be identified and promptly addressed. The first step in the care of a child with OAB should be the initiation of conservative treatment measures, which should be maintained throughout the course of therapy. Although oxybutynin is currently the only pharmacological treatment approved in North America for children with $O A B$, many alternatives have been studied and might be offered as off-label options until their eventual official approbation. Likewise, botulinum toxin injections and neuromodulation might be proposed in severe or refractory cases. Finally, patient and family education and setting realistic expectations of treatment efficacy should not be forgotten in the treatment armamentarium for children suffering from OAB.

Competing interests: Dr. Bolduc has received grant funding for clinical trials from Astellas Pharma and Pfizer Canada; has been a principal investigator for clinical projects associated with Astellas Pharma and Pfizer Canada on overactive bladder; and was the recipient of the Canadian Urological Association Scholarship Fund (CUASF) and CUA-Astellas research grants. Dr. Ramsay reports no competing personal or financial interests.

This paper has been peer-reviewed.

\section{References}

1. Austin PF, Bauer SB, Bower W, et al. The standardization of terminology of lower urinary tract function in children and adolescents: Update report from the standardization committee of the International Children's Continence Society. Neurourol Urodyn 2016;35:471-81. https://doi.org/10.1002/nau.22751

2. Franco I. Overactive bladder in children. Part 1: Pathophysiology. J Urol 2007;178:761-8. https://doi.org/10.1016/i.juro.2007.05.014

3. Kaijwara $M$, Inoue K, Kato $M$, et al. Nocturnal enuresis and overactive bladder in children: An epidemiological study. Int J Urol 2006;13:36-41.
4. Chung JM, Lee SD, Kang DI, et al. Prevalence and associated factors of overactive bladder in Korean children 5-13 years old: A nationwide multicenter study. Urology 2009;73:63-7. https://doi.org/10.1016/i. urology.2008.06.063

5. Bartoli S, Aguzzi G, Tarricone R. Impact on quality of life of urinary incontinence and overactive bladder: A systematic literature review. Urology 2010;75:491-500. https://doi.org/10.1016/i.urology.2009.07.1325

6. Landgraf JM, Abidari J, Cilento BG Jr, et al. Coping, commitment, and attitude: Quantifying the everyday burden of enuresis on children and their families. Pediatrics 2004;113:334-44. https://doi.org/10.1542/peds.113.2.334

7. Allen $H A$, Austin JC, Boyt MA, et al. Initial trial of timed voiding is warranted for all children with daytime incontinence. Urology 2007;69:962-5. https://doi.org/10.1016/i.urology.2007.01.049

8. Wiener JS, Scales MT, Hampton J, et al. Long-term efficacy of simple behavioural therapy for daytime wetting in children. J Urol 2000;164:786-90. https://doi.org/10.1016/S0022-5347(05)67313-2

9. Queiroz Machado V, Monteiro A, Pecanha A, et al. Slow transit constipation and lower urinary tract dysfunction. J Pediatr Urol 2015;11:357el-5.

10. Loening-Baucke $V$. Urinary incontinence and urinary tract infection and their resolution with treatment of chronic constipation of childhood. Pediatrics 1997;100:228-32. https://doi.org/10.1542/ peds. 100.2 .228

11. Tugtepe H, Thomas DT, Ergun R, et al. Comparison of biofeedback therapy in children with treatment-refractory dysfunctional voiding and overactive bladder. Urology 2015;85: 900-4. https://doi.org/10.1016/i. urology.2014.12.031

12. Chang SJ, Van Laecke E, Bauer SB, et al. Treatment of daytime urinary incontinence: A standardization document from the International Children's Continence Society. Neurourol Urodyn 2017;36:43-50. https://doi.org/10.1002/nau.22911

13. Greenfield SP, Fera M. The use of intravesical oxybutynin chloride in children with neurogenic bladder. J Urol 1991;146:532-4.

14. Massad CA, Kogan BA, Trigo-Rocha FE. The pharmacokinetics of intravesical and oral oxybutynin chloride. J Urol 1992;148:595-7.

15. Kasabian NG, Vlachiotis JD, Lais A, et al. The use of intravesical oxybutynin chloride in patients with detrusor hypertonicity and detrusor hyperreflexia. J Urol 1994;151:944-5.

16. Alloussi $S$, Murtz G, Braun R, et al. Efficacy, tolerability and safety of propiverine hydrochloride in comparison to oxybutynin in children with urge incontinence due to overactive bladder: Results of a multicentre observational cohort study. BJU Int 2010, 106:550-6. https://doi.org/10.1111/j.1464410X.2009.09129.x

17. Van Arendonk KJ, Knudson MJ, Austin JC, et al. Improved efficacy of extended release oxybutynin in children with persistent daytime urinary incontinence converted from regular oxybutynin. Urology 2006;68:862-5. https://doi.org/10.1016/j.urology.2006.04.034

18. Youdim K, Kogan BA. Preliminary study of the safety and efficacy of extended-release oxybutynin in children. Urology 2002;59:428-32. https://doi.org/10.1016/S0090-4295(01)01569-2

19. Reinberg Y, Crocker J, Wolpert J, et al. Therapeutic efficacy of extended release oxybutynin chloride, and immediate release and long-acting tolterodine tartrate in children with diurnal urinary incontinence. J Urol 2003;169:317-9. https://doi.org/10.1016/S0022-5347(05)64115-8

20. Gleason JM, Daniels C, Williams K, et al. Single-centre experience with oxybutynin transdermal system (patch) for management of symptoms related to non-neuropathic overactive bladder in children: An attractive, well-tolerated alternative form of administration. J Pediatr Urol 2014;10:753-7. https://doi.org/10.1016/i.jpurol.2013.12.017

21. Goldfischer ER, Sand PK, Thomas H, et al. Efficacy and safety of oxybutynin topical gel $3 \%$ in patients with urgency and/or mixed urinary incontinence: A randomized, double-blind, placebo-controlled study. Neurourol Urodyn 2015; 34:37-43. https://doi.org/10.1002/nau.22504

22. Staskin DR, Dmochowski RR, Sand PK, et al. Efficacy and safety of oxybutynin chloride topical gel for overactive bladder: A randomized, double-blind, placebo controlled, multicentre study. J Urol 2009;181:176472. htrps://doi.org/10.1016/i.juro.2008.11.125

23. Holland AJ, King PA, Chauvel PJ, et al. Intravesical therapy for the treatment of neurogenic bladder in children. ANZ J Surg 1997;67:731-3. https://doi.org/10.1111/j.1445-2197.1997.tb07119.x

24. Prasad KV, Vaidyanathan S. Intravesical oxybutynin chloride and clean intermittent catheterisation in patients with neurogenic vesical dysfunction and decreased bladder capacity. BJU 1993;72:719-22. https://doi.org/10.1111/i.1464-410X.1993.tb16255.x

25. Mizunaga $M$, Miyata $M$, Kaneko $S$, et al. Intravesical instillation of oxybutynin hydrochloride therapy for patients with a neuropathic bladder. Paraplegia 1994;32:25-9. https://doi.org/10.1038/ sc. 1994.5

26. Goess $\mathrm{C}$, Sauter T, Michael T, et al. Efficacy and tolerability of tolterodine in children with detrusor hyperreflexia. Urology 2000;55:414-8. https://doi.org/10.1016/S0090-4295(99)00477-X

27. Bolduc $S$, Upadhyay J, Payton J, et al. The use of tolterodine in children after oxybutynin failure. BJU Int 2003;91:398-401. https://doi.org/10.1046/i.1464-410X.2003.04085.x 
28. Medhi B, Mittal N, Bansal D, et al. Comparison of tolterodine with standard treatment in pediatric patients with non-neurogenic dysfunctional voiding/over active bladder: A systematic review. Indian J Physiol Pharmacol 2013;57:343-53.

29. Nijman RJ, Borgstein NG, Ellsworth $P$, et al. Long-term tolerability of tolterodine extended release in children 5-11 years of age: Results from a 12-month, open-label study. Eur Urol 2007;52:1511-6. https://doi.org/10.1016/i.eururo.2007.05.002

30. Mahotra $B$, Darsey $E$, Crownover $P$, et al. Comparison of pharmacokinetic variability of fesoterodine vs. tolterodine extended release in cytochrome P450 206 extensive and poor metabolizers. Br I Clin Pharmacol 2011;72:226-34. https://doi.org/10.1111/j.1365-2125.2011.03948.x

31. Malhotra B, El-Tahtawy A, Wang EQ, et al. Dose-escalating study of the pharmacokinetics and toerability of fesoterodine in children with overactive bladder. J Pediatr Urol 2012;8:336-42. https://doi.org/10.1016/i.jpurol.2012.02.008

32. Hoebeke P, De Pooter J, De Caestecker K, et al. Solifenacin for therapy resistant overactive bladder. J Urol 2009;182:2040-4. https://doi.org/10.1016/i.juro.2009.05.100

33. Bolduc $S$, Moore K, Nadeau $G$, et al. Prospective open label study of solifenacin for overactive bladder in children. J Urol 2010;184: 1668-73. https://doi.org/10.1016/i.juro.2010.03.124

34. Nadeau G, Schroder A, Moore K, et al. Long-term use of solifenacin in pediatric patients with overactive bladder: Extension of a prospective open-label study. Can Urol Assoc J 2014;8:118-23. https://doi.org/10.5489/cuaj.1356

35. Newgreen D, Bosman B, Sawyer W, et al. Solifenacin in children and adolescents with overactive bladder: Results of a phase 3 randomized clinical trial. Eur Urol 2016. [Epub ahead of print]. https://doi.org/10.1016/i.eururo.2016.08.061

36. Bosman B, Newgreen D, Sawyer W, et al. Solifenacin in children and adolescents with overactive bladder: Results of an open-label, long-term clinical trial. 26th European Society for Pediatric Urology Congress; Prague, Czech Republic, 2015.

37. Humphreys MR, Reinberg YE. Contemporary and emerging drug treatments for urinary incontinence in children. Paediatr Drugs 2005;7:151-62. https://doi.org/10.2165/00148581-200507030-00002

38. Madersbacher $\mathrm{H}$, Rovner E. Trospium chloride: The European experience. Expert Opin Pharmacother 2006;7:1373-80. https://doi.org/10.1517/14656566.7.10.1373

39. Wright $A$, Clothier J. Trospium: A useful alternative antimuscarinic in children with emotional behavioura disorders. 26th European Society for Pediatric Urology Congress; Prague, Czech Republic, 2015.

40. Marschall-Kehrel D, Feustel C, Persson de Geeter C, et al. Treatment with propiverine in children suffering from non-neurogenic overactive bladder and urinary incontinence: Results of a randomized, placebo-controlled, phase 3 cinical trial. Eur Urol 2009:55:729-36. https://doi.org/10.1016/i.eururo.2008.04.062

41. Kim WJ, Lee DG, Lee SW, et al. Efficacy and safety of propiverine in children with overactive bladder. Kor J Urol 2012;53:275-9. hitps://doi.org/10.4111/kju.2012.53.4.275

42. Sacco $E$, Bientinesi R. Mirabegron: A review of recent data and its prospects in the management of overactive bladder. Ther Adv Urol 2012;4:315-24. https://doi.org/10.1177/1756287212457114

43. Herschorn S, Barkin J, Castro-Diaz D, et al. A phase 3, randomized, double-blind, parallel-group, placebo-controlled, multicentre study to assess the efficacy and safety of the beta(3) adrenoceptor agonist, mirabegron, in patients with symptoms of overactive bladder. Urology 2013;82:313-20. https://doi.org/10.1016/i.urology.2013.02.077

44. Nitti VW, Khullar V, van Kerrebroeck P, et al. Mirabegron for the treatment of overactive bladder: A prespecified pooled efficacy analysis and pooled safety analysis of three randomized, double-blind, placebocontrolled, phase 3 studies. Int J Clin Pract 2013;67:619-32. https://doi.org/10.1111/iicp.12194

45. Herschorn $S$, Kowey P, Nitti VW, et al. Cardiovascular (CV) assessments in short- and long-erm phase 3 mirabegron trials in patients with overactive bladder (OAB). Eur Urol 2013;12:739-40. https://doi.org/10.1016/S1569-9056(13)61221-X

46. Blais A, Nadeau $G$, Moore K, et al. Prospective pilot study of mirabegron in pediatric patients with overactive bladder. Eur Urol 2016;70:9-13. https://doi.org/10.1016/..eururo.2016.02.007

47. Bolduc $S$, Moore K, Lebel $S$, et al. Double antimuscarinic therapy for refractory overactive bladder. J Urol 2009;182:2033-8. https://doi.org/10.1016/i.juro.2009.05.099

48. Nadeau G, Schroder A, Moore K, et al. Double antimuscarinic therapy for refractory neurogenic and non-neurogenic detrusor overactivity in children: Long-term results of a prospective, open-label study. Can Urol Assoc J 2014;8:175-80. https://doi.org/10.5489/cuaj.1362

49. Morin $F$, Blais $A$, Nadeau $G$, et al. Dual therapy for refractory overactive bladder in children: A prospective, open-label study. J Urol 2016. [Epub ahead of print]. htrps://doi.org/10.1016/i.juro.2016.11.101

50. Fahmy A, Youssif $M$, Rhashad $H$, et al. Combined low-dose antimuscarinics for refractory detrusor overactivity in children. J Ped Urol 2016;12:219.e1-5. https://doi.org/10.1016/i.jpurol.2016.04.023

51. Sicras-Mainar A, Rejas J, Navarro-Artieda R, et al. Antimuscarinic persistence patterns in newly treated patients with overactive bladder: A retrospective comparative analysis. Int Urogynecol J 2014;25:485-92. https://doi.org/10.1007/s00192-013-2250-4

52. Fortin $A$, Morin V, Ramsay $S$, et al. Adherence to antimuscarinics in children with overactive bladder. Pediatr Child's Health 2016. [Epub ahead of print].
53. Wagg A, Compion G, Fahey A, et al. Persistence with prescribed antimuscarinic therapy for overactive bladder: A UK experience. BJU Int 2012;110:1767-74. https://doi.org/10.1111/i.1464410X.2012.11023.X

54. Blais $A$, Bergeron $M$, Nadeau $G$, et al. Antimuscarinic use in children: Persistence and patterns of therapy. Can Urol Assoc J 2016;10:137-40. https://doi.org/10.5489/cuai.3527

55. Apostolidis $A$, Dasgupta $P$, Denys $P$, et al. Recommendations on the use of botulinum toxin in the treatment of lower urinary tract disorders and pelvic floor dysfunctions: A European consensus report. Eur Urol 2009:55:100-19. htrps://doi.org/10.1016/i.eururo.2008.09.009

56. Hoebeke P, De Caestecker K, Vande Walle J, et al. The effect of botulinum-A toxin in incontinent children with therapy resistant overactive detrusor. J Urol 2006;176:328-30. https://doi.org/10.1016/ S0022-5347(06)00301-6

57. Game $X$, Mouracade $P$, Chartier-Kastler E, et al. Botulinum toxin-A (Botox) intradetrusor injections in children with neurogenic detrusor overactivity/neurogenic overactive bladder: A systematic literature review. J Pediatr Urol 2009;5:156-64. https://doi.org/10.1016/i.jpurol.2009.01.005

58. Greer T, Abbott J, Breytenbach W, et al. Ten years of experience with intravesical and intrasphincteric onabotulinumtoxinA in children. J Pediatr Urol 2016;12:94el-6.

59. Berger $D$, Berger $K$, Genton N. Endovesical transurethral electrostimulation in the rehabilitation of neurogenic bladder in children: 4 years' clinical experience. Eur Urol 1978;4:33-45.

60. Kaplan WE, Richards I. Intravesical bladder stimulation in myelodysplasia. J Urol 1988;140:1282-4.

61. Boone TB, Roehrborn CG, Hurt $G$. Transurethral intravesical electrotherapy for neurogenic bladder dysfunction in children with myelodysplasia: A prospective, randomized clinical trial. J Urol 1992;148:550-4.

62. Trsinar B, Kraij B. Maximal electrical stimulation in children with unstable bladder and nocturnal enuresis and/or daytime incontinence: A controlled study. Neurourol Urodyn 1996;15:133-42. https://doi.org/10.1002/(SICI) 1520-6777(1996) 15:2<133::AID-NAU2>3.0.C0;2-6

63. Kaibafzadeh AM, Sharifi-Rad L, Baradaran N, et al. Effect of pelvic floor interferential electrostimulation on urodynamic parameters and incontinency of children with myelomeningocele and detrusor overactivity. Urology 2009;74:324-9. https://doi.org/10.1016/j.urology.2008.12.085

64. Hoebeke $P$, Van Laecke E, Everaert $K$, et al. Transcutaneous neuromodulation for the urge syndrome in children: A pilot study. J Urol 2001;166:2416-9. https://doi.org/10.1016/S0022-5347(05)65605-4

65. Malm-Buatsi E, Nepple KG, Boyt MA, et al. Efficacy of transcutaneous electrical nerve stimulation in children with overactive bladder refractory to pharmacotherapy. Urology 2007;70:980-3. https://doi.org/10.1016/i.urology.2007.06.1109

66. Lordelo $\mathrm{P}$, Teles $\mathrm{A}$, Veiga ML, et al. Transcutaneous electrical nerve stimulation in children with overactive bladder: A randomized clinical trial. J Urol 2010;184:683-9. https://doi.org/10.1016/i. juro.2010.03.053

67. Hagstroem $S$, Mahler B, Madsen B, et al. Transcutaneous electrical nerve stimulation for refractory daytime urinary urge incontinence. J Urol 2009;182:2072-8. https://doi.org/10.1016/i.juro.2009.05.101

68. Tugtepe $H$, Thomas DT, Ergun $R$, et al. The effectiveness of transcutaneous electrical neural stimulation therapy in patients with urinary incontinence resistant to initial medical treatment or biofeedback. J Pediatr Urol 2015;11:137e1-5.

69. Sillen $\mathrm{U}$, Arwidsson C, Doroszkiewicz $\mathrm{M}$, et al. Effects of transcutaneous neuromodulation (TENS) on overactive bladder symptoms in children: A randomized, controlled trial. J Pediatr Urol 2014;10:1100-5. https://doi.org/10.1016/i.jpurol.2014.03.017

70. Quintiliano $F$, Veiga ML, Moraes M,et al. Transcutaneous parasacral electrical stimulation vs. oxybutynin for the treatment of overactive bladder in children: A randomized clinical trial. J Urol 2015;193:1749-53. https://doi.org/10.1016/i.juro.2014.12.001

71. Hutchinson R, Garriboli M, Clothier J, et al. Is parasacral neuromodulation using TENS a costeffective first-line treatment for bladder overactivity in children? 26th European Society for Paediatric Urology Congress; Prague, Czech Republic, 2015.

72. Capitanucci ML, Camanni D, Demelas F, et al. Long-term efficacy of percutaneous tibial nerve stimulation for different types of lower urinary tract dysfunction in children. J Urol 2009;182:2056-61. htrps://doi.org/10.1016/i.juro.2009.03.007

73. Patidar $N$, Mittal $V$, Kumar $M$, et al. Transcutaneous posterior tibial nerve stimulation in pediatric overactive bladder: A preliminary report. J Pediatr Urol 2015;11:351 el-6.

74. Boudaoud N, Binet A, Line A, et al. Management of refractory overactive bladder in children by transcutaneous posterior tibial nerve stimulation: A controlled study. J Pediatr Urol 2015;11:138 el-10.

75. Schober MS, Sulkowski JP, Lu PL, et al. Sacral nerve stimulation for pediatric lower urinary tract dysfunction: Development of a standardized pathway with objective urodynamic outcomes. I Urol 2015;194:1721-7. htrps://doi.org/10.1016/i.juro.2015.06.090

Correspondence: Dr. Stéphane Bolduc, Division of Urology, CHU de Québec-Université Laval (CHUL) Quebec City, QC, Canada; stephane.bolduc@fmed.ulaval.ca 